\title{
Genetic testing approaches for hereditary breast cancer: Perspectives from a private diagnostic laboratory
}

\author{
D C Smith, PhD; S A Gardiner, MSc Med (Genetic Counselling); M Conradie, MB ChB, DCH, FCMG (SA) MMed (Medical Genetics); \\ J Gerber, MSc; F Loubser, MSc Med (Genetic Counselling)
}

Molecular Laboratory, Drs Dietrich, Voigt, Mia \& Partners (PathCare) Reference Laboratory, Cape Town, South Africa

Corresponding author: D C Smith (danielle.smith@pathcare.org)

Breast cancer is highly prevalent in South Africa, and up to $10 \%$ of breast cancer cases may be hereditary. The landscape of genetic testing options for hereditary breast cancer (HBC) has changed significantly over the past decade, and healthcare providers are faced with multiple options when referring breast cancer patients for genetic testing. We have performed a retrospective study of 3 years' worth of breast cancer genetic testing referrals to our laboratory. While Afrikaner and Ashkenazi Jewish founder screens may be appropriate as first-line tests in a limited subset of patients, we have shown that in the majority of cases it is more effective to adopt a multigene panel approach. While variants in the BRCA1 and BRCA2 genes still account for a significant proportion of cases, close to $40 \%$ of pathogenic variants were found in genes other than BRCA1 or BRCA2. There are many factors that healthcare providers should consider when requesting genetic testing for breast cancer patients and families, including family history, ancestral background, cost, medical aid scheme reimbursement and scope of testing. We summarise our findings and provide advantages and disadvantages of each approach, with the aim of assisting clinicians and genetic counsellors to make appropriate testing decisions.

S Afr Med J 2020:110(10):988-992. https://doi.org/10.7196/SAMJ.2020.v110i10.14709

Breast cancer is the most common malignancy in South African (SA) women, accounting for $\sim 22 \%$ of local cancer cases, ${ }^{[1]}$ and $5-10 \%$ of these cases are considered to be hereditary. ${ }^{[2]}$ Historically, hereditary breast cancer (HBC) was associated primarily with pathogenic variants in the $B R C A 1$ and $B R C A 2$ genes, but in the post-genomic era there is increasing evidence of the contributions of other genes to inherited breast cancer risk. ${ }^{[3,4]}$ This means that clinicians and genetic counsellors are faced with an ever-broadening menu of genetic testing options for patients. Our colleagues have published on strategies for patients in the public healthcare sector, ${ }^{[5-7]}$ but no data are available on the detection rates of the various testing options available to SA patients in the private sector. Information regarding the detection rates of these tests may assist managing healthcare providers to select the most appropriate and economical approach to genetic testing for individuals and families with HBC.

\section{Indications for genetic testing}

Various international groups have proposed guidelines and criteria for identifying candidates for genetic testing. ${ }^{[8-10]}$ However, other groups have raised concerns about these criteria being too stringent, resulting in more than half of patients harbouring disease-causing variants being missed. ${ }^{[11]}$ In line with these findings, the American Society of Breast Surgeons recommends that genetic testing be made available to all patients with a personal history of breast cancer, ${ }^{[12]}$ although this approach in patients diagnosed at $>65$ years without a significant family history of relevant cancers has a very low probability $(<2 \%)$ of yielding results with clinical utility. ${ }^{[3,8]}$

Currently no national SA consensus guidelines exist for genetic testing for persons at risk of HBC. Individual academic units and genetic practitioners have adapted international guidelines ${ }^{[8-10]}$ to our local context, taking into consideration founder effects among certain population groups and the availability of tests in different healthcare sectors. ${ }^{[5-7]}$
It is internationally recognised and recommended that any genetic testing be performed in the context of appropriate genetic counselling. This process aims to ensure informed consent by providing the patient with information regarding testing, including the benefits, risks and limitations of different testing options. The potential complexities of results, including the chance of identifying variants of uncertain clinical significance (VUSs), and the implications of results for the family are also discussed. ${ }^{[3,7,8]}$

\section{Overview of current genetic testing strategies in the private sector}

\section{Founder screening}

In the local context, founder variant testing may be requested as a first-line genetic test for individuals of Ashkenazi Jewish or Afrikaner ancestry. ${ }^{[-7,713]}$ It is important to note that there are $>2000$ and $>3000$ known 'likely pathogenic' and 'pathogenic' variants in the BRCA1 and $B R C A 2$ genes, respectively (as listed in ClinVar), and each founder screen tests for only three of these variants (Table 1). It is therefore not appropriate to utilise these tests as first-line screening for individuals who are not of known Afrikaner or Jewish ancestry. Additionally, individuals who have negative results from these limited founder screens should be offered more extensive testing options, such as full sequencing of the BRCA1 and BRCA2 genes.

\section{$B R C A 1$ and $B R C A 2$ full gene sequencing}

For patients who are not of known Afrikaner or Ashkenazi Jewish ancestry, clinicians may request comprehensive screening of the full $B R C A 1$ and BRCA2 genes, or utilise multigene panels that include additional high- or moderate-risk genes such as PALB2, CHEK2 and ATM. Germline disease-causing variants in BRCA1 and BRCA2 are estimated to account for $\sim 24 \%$ of families with inherited breast and/or ovarian cancer in European populations. ${ }^{[8]}$ Comprehensive screening of the full coding regions of genes is usually achieved via a next- 
Table 1. Summary of genetic testing options

\begin{tabular}{|c|c|c|c|c|}
\hline & Afrikaner founder screen & Ashkenazi Jewish founder screen & BRCA1/2 sequencing (local) & Multigene panel (international) \\
\hline Details & $\begin{array}{l}\text { 3 variants } \\
\text { - } \text { BRCA1 c.1374delC } \\
\text { (p.Asp458Glufs) } \\
\text { - } \\
\text { BRCA1 c.2641G }>\mathrm{T} \\
\text { (p.Glu881Ter) } \\
\text { - } \\
\text { BRCA2 c.7934delG } \\
\text { (p.Arg2645Asnfs) }\end{array}$ & 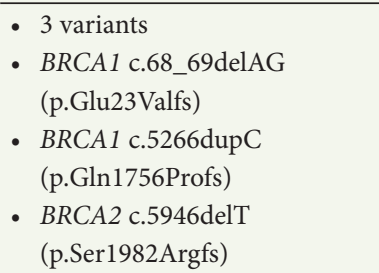 & $\begin{array}{l}\text { Sequencing of } B R C A 1 \\
\text { and } B R C A 2 \text { genes }(>5000 \\
\text { variants) }\end{array}$ & $\begin{array}{l}\text { Sequencing of multiple genes, } \\
\text { including } B R C A 1, B R C A 2 \text {, } \\
\text { CHEK2, ATM }\end{array}$ \\
\hline $\operatorname{Cost}^{*}$ & ZAR2 200 & ZAR2 200 & $\begin{array}{l}\text { ZAR13 } 500 \text { (varies } \\
\text { between laboratories) }\end{array}$ & $\begin{array}{l}\text { ZAR4 } 600 \\
\text { (USD250 + ZAR750 courier/ } \\
\text { handling fee) }\end{array}$ \\
\hline Turnaround time & 1 - 2 weeks & 1 - 2 weeks & 6 - 8 weeks & $\begin{array}{l}2 \text { - } 3 \text { weeks } \\
\left(1 \text { week for STAT Panel }{ }^{\dagger}\right)\end{array}$ \\
\hline Disadvantages & $\begin{array}{l}\text { Only } 3 \text { variants tested } \\
\text { Not appropriate for } \\
\text { individuals of other } \\
\text { ancestries }\end{array}$ & $\begin{array}{l}\text { Only } 3 \text { variants tested } \\
\text { Not appropriate for individuals } \\
\text { of other ancestries }\end{array}$ & $\begin{array}{l}\text { Risk of missing } 40 \text { - } 50 \% \text { of } \\
\text { pathogenic variants in other } \\
\text { HBC-associated genes } \\
\text { Long turnaround times } \\
\text { Patient may need to pay a } \\
\text { significant proportion of } \\
\text { cost }\end{array}$ & $\begin{array}{l}\text { High VUS rates } \\
\text { Rarely covered by medical aid }\end{array}$ \\
\hline Advantages & $\begin{array}{l}\text { Cost-effective first-line } \\
\text { test for individuals with } \\
\text { Afrikaner ancestry } \\
\text { May be covered (in full } \\
\text { or partially) by medical } \\
\text { aid scheme }\end{array}$ & $\begin{array}{l}\text { Cost-effective first-line test for } \\
\text { individuals with Ashkenazi } \\
\text { Jewish ancestry } \\
\text { May be covered (in full or } \\
\text { partially) by medical aid scheme }\end{array}$ & $\begin{array}{l}\text { Higher detection rates than } \\
\text { founder screens } \\
\text { May be covered (in full or } \\
\text { partially) by medical aid } \\
\text { scheme }\end{array}$ & $\begin{array}{l}\text { High detection rates } \\
\text { Short turnaround times } \\
\text { Free testing available for } \\
\text { family members }\end{array}$ \\
\hline
\end{tabular}

generation sequencing (NGS) approach. It is important to select an approach that includes deletion/duplication analysis (either through NGS analysis or complementary methods such as multiplex ligationdependent probe amplification (MLPA)) since $~ 10 \%$ of pathogenic variants in BRCA1 and BRCA2 can only be detected in this manner. ${ }^{[14]}$ Although the cost of NGS-based testing has decreased substantially in the past decade, local NGS-based testing still comes with a significant cost and turnaround times of more than 6 weeks (Table 1).

\section{Multigene panels}

More recently, research has shown that more than half of the diseasecausing variants underlying $\mathrm{HBC}$ can be found in genes other than $B R C A 1$ and BRCA2 ${ }^{[15]}$ These non-BRCA genes include ATM, CHEK2 and PALB2, among others, and are also tested using an NGS-based approach. Multigene panel tests including these genes are available locally, although many clinicians and genetic counsellors opt to refer to the international laboratory Invitae (USA) because of the lower costs, quicker turnaround time, and additional benefits such as testing of family members at no additional cost if a clinically relevant variant is identified (Table 1). No data are available on the uptake of local multigene panel tests.

The laboratory where the study was conducted does not offer in-house multigene panel testing for $\mathrm{HBC}$, but sends these requests to Invitae laboratory. Multigene panels offered by other local laboratories are not included in this article.

When referring for multigene panel testing, it is important to consider the likelihood of detecting VUSs. This risk increases the more genes the panel selected contains. Rather than falling into pathogenic or benign categories, these are sequence variants for which the association with disease risk is unclear based on currently available evidence. Laboratories routinely report on VUS results to allow for periodic review and potential reclassification based on new evidence. However, until a VUS is reclassified, these variants should not be used in clinical decision-making. ${ }^{[16]}$

\section{Medical aid scheme considerations}

The selection of tests in the private sector is often influenced by cost and medical aid scheme reimbursement. Medical aid schemes do not currently cover tests sent to international referral laboratories. Patients may apply to their medical scheme for reimbursement of local genetic testing, but this is often subject to internal risk assessment criteria, which differs per scheme. In our experience, the full cost of local BRCA1 and BRCA2 sequencing has rarely been covered by medical schemes, and patients often had out-of-pocket expenses of a significant proportion. In recent months it has become evident that more medical schemes are reimbursing these local tests in full; this option may therefore become more attractive to patients and healthcare providers. It is advisable for patients and their healthcare team to discuss the economic impact of all testing options, both local and international, and apply to medical schemes for approval prior to any testing.

\section{Methods}

An internal database was reviewed to determine the results obtained from $\mathrm{HBC}$ patient referrals to our laboratory over a period of 3 years (2016 - 2018). This period was selected since it represented the most comprehensive data set for the various testing options. All referrals were included in the data set, except for referrals for family variant 
testing (testing of at-risk individuals in a family where a known pathogenic variant has been detected) which were excluded. Referrals came from private clinicians ranging from general practitioners to specialist physicians and genetic specialists throughout SA. The results from founder screens $(n=704)$, in-house BRCA1/2 sequencing $(n=260)$ and internal multigene panel send-aways $(n=723)$ were de-identified and reviewed to determine the positive and negative pick-up rates for each test. The VUS rate was also calculated for multigene panel tests. Clinical and demographic information rarely accompanies these referrals. It was therefore not possible to determine how appropriate requests were, based on the patients' ancestral backgrounds.

\section{Ethics approval}

Ethics approval was granted by the University of the Free State Health Sciences Research Ethics Committee (ref. no. UFSHSD2019/0484/2805).

\section{Resullts}

\section{Founder screening}

Based on 655 requests for Afrikaner variant testing, 15\% of results were positive for one of the three variants tested (Fig. 1). This is significantly lower than the detection rates which can be achieved in well-defined Afrikaner cohorts. ${ }^{[5,6]}$ The most commonly detected variant was $B R C A 2$ c.7934del (p.Arg2645Asnfs, historically referred to as $B R C A 28162 \mathrm{delG}$ ) which was detected in $11 \%$ of referrals. This is in line with variant distributions reported in other local studies. ${ }^{[5,6]}$

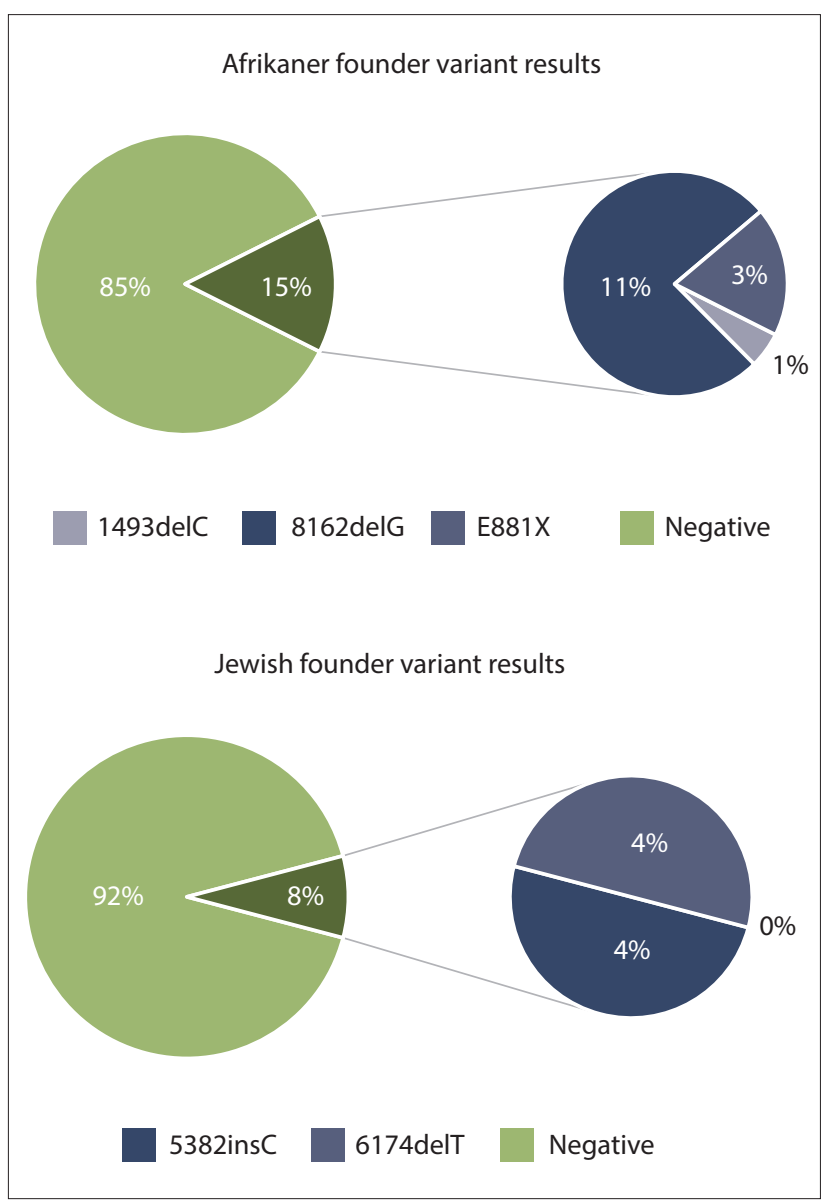

Fig. 1. Results of in-house founder variant tests over a period of 3 years (2016 - 2018).
Fewer requests were received for Ashkenazi Jewish founder variant screening $(n=49)$. Eight percent of these requests were positive for either the BRCA1 c.5266dupC (p.Gln1756Profs) or BRCA2 c.5946delT (p.Ser1982Argfs) variants (Fig. 1). No individuals were positive for the BRCA1 c.68_69delAG (p.Glu23Valfs) variant.

\section{Sequencing of the $B R C A 1$ and $B R C A 2$ genes}

Based on 260 referrals for BRCA1 and BRCA2 NGS-based sequencing over a 3 -year period, we noted a $7 \%$ pathogenic variant pick-up rate. Sixty-five percent of disease-causing variants were found in $B R C A 1$ (Fig. 2), which is in line with internationally published distributions of BRCA1 v. BRCA2 disease-causing variants $(66 \%$ v. $34 \%) .^{[14]}$

\section{Multigene panels}

From a dataset of $>700$ referrals to Invitae for multigene panel testing, we noted a positive pick-up rate ranging between $17 \%$ and $21 \%$, depending on the panel selected. The 9-gene Breast Cancer STAT Panel (consisting of BRCA1, BRCA2, CDH1, PALB2, PTEN, STK11, TP53, ATM and CHEK2) showed the highest pick-up rate of $21 \%$ (Fig. 3). The 20-gene Breast and Gyn Cancers Guidelines-Based Panel and the 47-gene Common Hereditary Cancers Panel showed positive pick-up rates of $17 \%$ and $19 \%$, respectively. We acknowledge that referrals for the STAT Panel may be biased towards affected patients in terms of needing an urgent result for clinical decision-making, compared with other panels that may include unaffected patients where no affected family member is available to test.

The risk of a higher VUS rate when larger panels are used is demonstrated in Fig. 3, with the largest 47-gene panel having a VUS pick-up rate of $56 \%$. When a VUS is reported, the result is neither actionable nor completely reassuring; the interpretation is therefore complex and should take the family history as well as other clinical factors into account. The higher the VUS rate, the more difficult the result becomes to interpret, and these results become more challenging to convey and explain to the patient. ${ }^{[3]}$

\section{Multigenes and multidisciplinary teams}

As mentioned previously, it is now possible to test for genetic contributions to $\mathrm{HBC}$ other than BRCA1 and BRCA2. Based on our referrals for multigene panel testing, close to $40 \%$ of disease-causing variants were found in genes other than BRCA1 or BRCA2 (Fig. 4). This highlights the importance of comprehensive genetic testing, since the clinical management and associated risks of breast, ovarian and other cancers (such as colon, gastric or prostate cancer) vary greatly, depending on the causative gene. ${ }^{[8]}$ Larger panels could also include genes that are relatively newly identified, with the implication

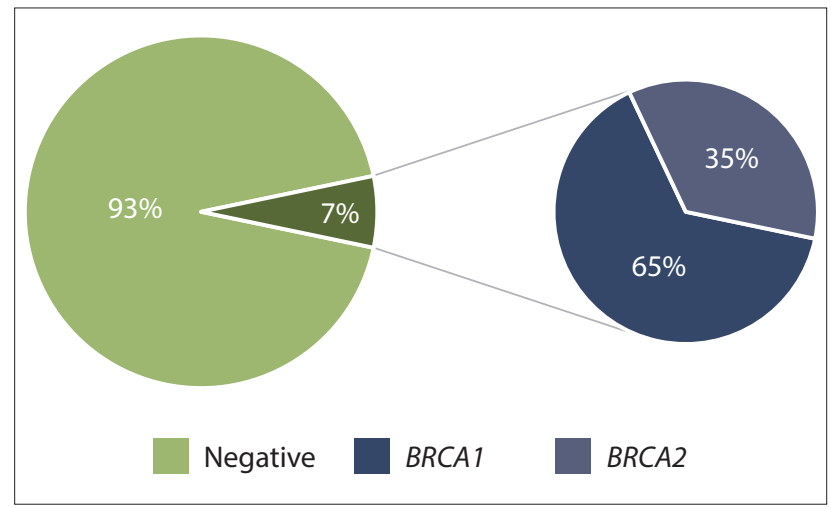

Fig. 2. Results of in-house BRCA1 and BRCA2 next-generation sequencingbased screening. 


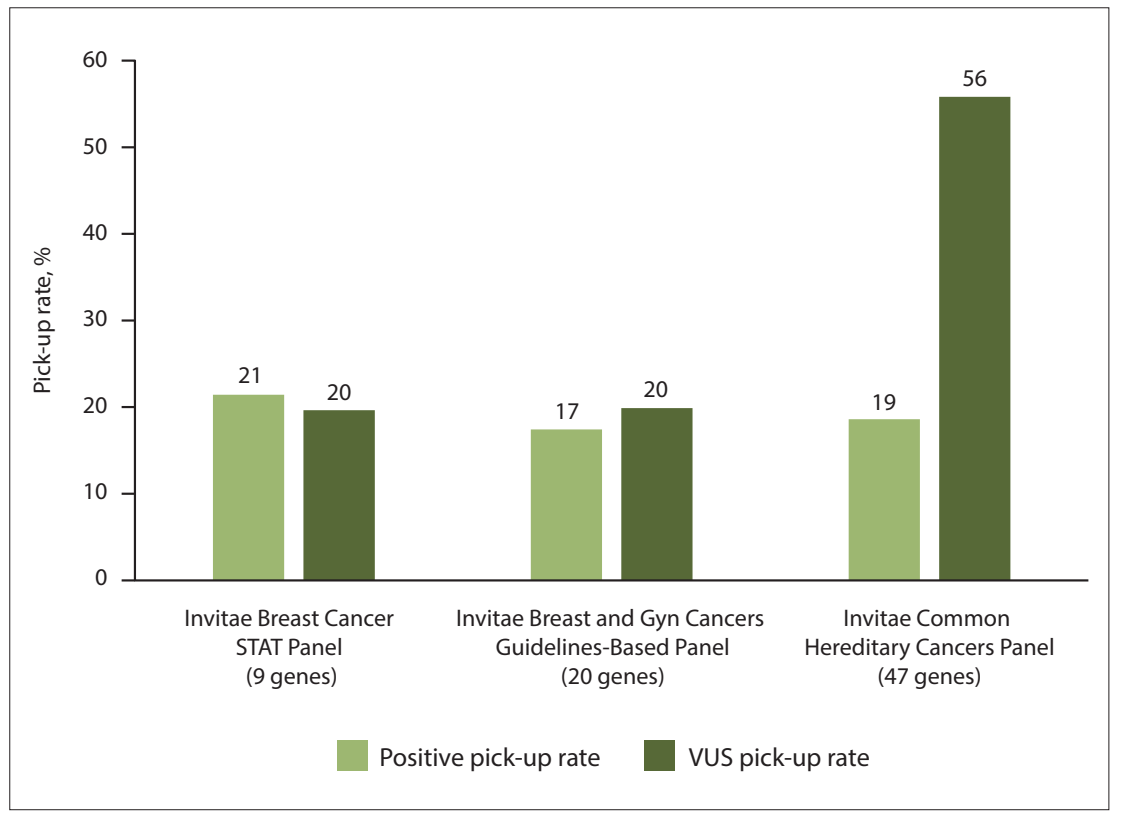

Fig. 3. Results of referrals to Invitae for multigene panel testing. (STAT Panel = BRCA1, BRCA2, CDH1, PALB2, PTEN, STK11, TP53, ATM and CHEK2; VUS = variant of uncertain significance.)

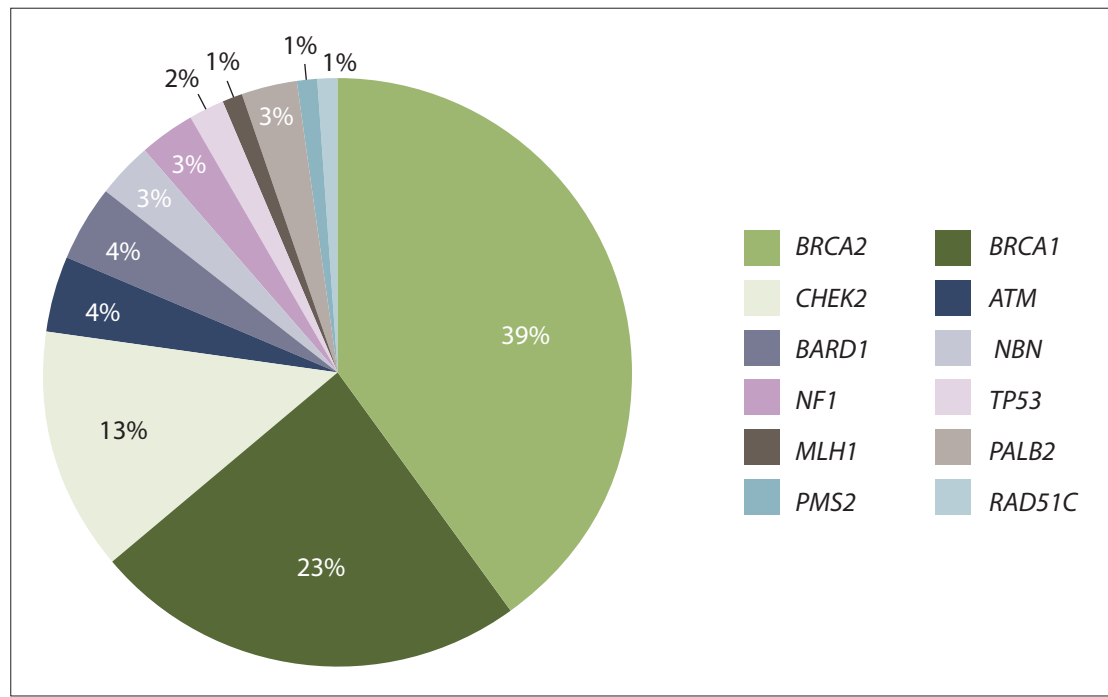

Fig. 4. Multigene panel results.

that cancer risks are not well delineated and no guidelines exist for medical management or the value of family predictive testing. ${ }^{[3]}$ Caution should be exercised when selecting a panel in which these genes are included.

\section{Discussion}

This retrospective study is the first to evaluate and compare the results obtained from different genetic testing options for $\mathrm{HBC}$ in the SA private sector. A summary of these testing options is given in Table 1 . A summary of the test details and positive pick-up rates is provided in Table 2.

The results of this study are in line with findings from other international publications in terms of positive pick-up rates for the multigene panels and VUS these six founder variants, in addition to other variants in BRCA1 and BRCA2 and the other $\mathrm{HBC}$-associated genes in the panel selected.

Our data suggest that in the private sector in SA, targeted multigene panels (such as the Invitae Breast Cancer STAT or the Invitae Hereditary Breast and Gyn Cancers Guidelines-Based Panel in this data set) are appropriate testing options for patients with suspected HBC. While positive pickup rates are high (17-21\%), the VUS rate is lower than with larger panels such as the Invitae Common Hereditary Cancer Panel ( $20 \%$ v. $56 \%)$, making result interpretation less complex. While the pick-up rate for multigene panels is much higher than with $B R C A 1$ and BRCA2 sequencing alone (17 $21 \%$ v. $7 \%$ ), the cost is also lower with the international multigene panels than local full gene sequencing of BRCA1 and BRCA2 (Table 1). Therefore, considering both cost and pick-up rate, the international send-away multigene panels may be a more suitable option for patients than local BRCA1 and $B R C A 2$ sequencing. However, it is essential that patients and healthcare providers engage with medical schemes prior to any genetic testing, since schemes are covering local NGS-based testing more frequently.

We have alluded to some of the complexities involved in choosing the most appropriate genetic testing approach for breast/ovarian cancer patients, as well as the intricacies that may arise with the interpretation of genetic testing results. For these reasons it is recommended that multigene testing is ideally offered in the context of professional genetic expertise for pre- and post-test genetic counselling. ${ }^{[3,8]}$ Genetic counselling services are still underutilised throughout SA and only available in some of the larger centres, ${ }^{[20]}$ although the majority of genetic counsellors in private practice offer telephonic or videocall consultations. Patients may also be referred to genetic services within the major academic hospitals.

\section{Conclusions}

In the SA private sector, multigene panel tests for HBC have good clinical utility in terms of pick-up rate for pathogenic variants. Founder mutation screens should only be requested in very specific contexts. Decisions regarding test options and interpretation of results can be complex and genetic counselling by genetic specialists is advised.

While national capacity building is important in order to expand the scope of local genetic services, the significantly lower costs of the international send-away panels 
Table 2. Summary of test details and positive pick-up rates

\begin{tabular}{|c|c|c|c|c|}
\hline & Afrikaner founder screen & Ashkenazi Jewish founder screen & BRCA1/2 sequencing (local) & Multigene panel (international) \\
\hline Details & 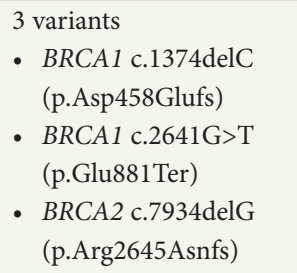 & $\begin{array}{l}3 \text { variants } \\
\text { - } B R C A 1 \text { c.68_69delAG } \\
\text { (p.Glu23Valfs) } \\
\text { - } B R C A 1 \text { c.5266dupC } \\
\text { (p.Gln1756Profs) } \\
\text { - } B R C A 2 \text { c.5946delT } \\
\text { (p.Ser1982Argfs) }\end{array}$ & $\begin{array}{l}\text { Sequencing of } B R C A 1 \text { and } \\
B R C A 2 \text { genes ( }>5000 \text { variants) }\end{array}$ & $\begin{array}{l}\text { Sequencing of multiple genes, } \\
\text { including } B R C A 1, B R C A 2 \text {, } \\
C H E K 2, A T M\end{array}$ \\
\hline $\begin{array}{l}\text { Number of } \\
\text { referrals }\end{array}$ & 655 & 49 & 260 & 723 \\
\hline $\begin{array}{l}\text { Positive } \\
\text { pick-up rate }\end{array}$ & $15 \%$ & $8 \%$ & $7 \%$ & $17-21 \%$ \\
\hline
\end{tabular}

make this option an attractive alternative. Further discussion is needed among product distributors, testing laboratories, healthcare providers, medical schemes, patients and their families, in order to increase the availability and accessibility of necessary genetic testing services in SA.

\section{Study limitations}

This study was conducted at a single laboratory in private practice in SA and results are therefore biased towards a population group having access to private medical schemes or an income level that would support self-payment for tests. Only data and testing options available for this laboratory were included in the article.

A correlation was not made between the pick-up rate of tests and the patient clinical information, as these data were not available.

Declaration. None.

Acknowledgements. We would like to acknowledge the staff of the PathCare Molecular laboratory, particularly Petra Raimond, Ilze Uys and Janine Blanckenberg, for their assistance with generating in-house results. Author contributions. DCS and SAG contributed to conceptualisation, design, analysis and interpretation of data, and drafted the manuscript. MC, JG and FL assisted with interpretation and critical revision of data and the manuscript. All authors approved the version to be published.

\section{Funding. None.}

Conflicts of interest. None.

1. South African National Cancer Registry 2014. https://www.nicd.ac.za/wp-content/ uploads/2019/12/2014-NCR-tables.pdf (accessed 16 August 2019).

2. Economopoulou P, Dimitriadis G, Psyrri A. Beyond BRCA: New hereditary breast cancer susceptibility genes. Cancer Treat Rev 2015;41(1):1-8. https://doi.org/10.1016/j.ctrv.2014.10.008

3. Peshkin BN, Isaacs C. Genetic testing and management of individuals at risk of hereditary breast and ovarian cancer syndromes. UpToDate. https://www.uptodate.com/contents/genetic-testing-andmanagement-of-individuals-at-risk-of-hereditary-breast-and-ovarian-cancer-syndromes (accessed 20 May 2020).

4. Peshkin BN, Isaacs C. Overview of hereditary breast and ovarian cancer syndromes associated with genes other than BRCA1/2. UpToDate. https://www.uptodate.com/contents/overview-of-hereditary-breastand-ovarian-cancer-syndromes-associated-with-genes-other-than-brcal-2 (accessed 20 May 2020).
5. Schoeman M, Apffelstaedt JP, Baatjes K, Urban M. Implementation of a breast cancer genetic service in South Africa - lessons learned. S Afr Med J 2013;103(8):529-533. https://doi.org/10.7196/SAMJ.6814

6. Seymour HJ, Wainstein T, Macaulay S, Haw T, Krause A. Breast cancer in high-risk Afrikaner families: Is BRCA founder mutation testing sufficient? S Afr Med J 2016;106(3):264-267. https://doi. families: Is BRCA founder mutation

7. Scott CJ, Schoeman M, Urban MF. Cancer genetics: An approach to suspected hereditary breast or Scott CJ, Schoeman M, Urban MF. Cancer genetics: An approach to suspected hereditary breast or
colorectal cancer. S Afr Med J 2019;109(4):214-218. https://doi.org/10.7196/SAMJ.2019.v109i4.13992 8. Daly MB, Pilarski R, Berry M, et al. NCCN Guidelines Insights: Genetic/Familial High-Risk Daly MB, Pilarski R, Berry M, et al. NCCN Guidelines Insights: Genetic/Familial High-Risk
Assessment: Breast and Ovarian, Version 2.2017. J Natl Compr Cancer Netw 2017;15(1):9-20. https:// Assessment: Breast and Ovarian,
doi.org/10.6004/jnccn.2017.0003

doi.org/10.6004/jnccn.2017.0003 American College of Medical Genetics and Genomics Professional Practice and Guidelines Committee and National Society of Genetic Counselors Practice Guidelines Committee. A practice guideline from the American College of Medical Genetics and Genomics and the National Society of Genetic Counselors: Referral indications for cancer predisposition assessment. Genet Med 2015;17(1):70-87. https://doi.org/10.1038/gim.2014.147

10. National Institute for Health and Care Excellence (NICE) (UK). Familial Breast Cancer: Classification, Care and Managing Breast Cancer and Related Risks in People With a Family History of Breast Cancer London: NICE: 2013 (updated 2019), https:// https://www.nice.org uk/guidance/cg164/ (accessed 9 September 2020).

11. Beitsch PD, Whitworth PW, Hughes K, et al. Underdiagnosis of hereditary breast cancer: Are genetic Beitsch PD, Whitworth PW, Hughes K, et al. Underdiagnosis of hereditary breast cancer: Are genetic
testing guidelines a tool or an obstacle? I Clin Oncol 2019;37(6):453-460. https://doi.org/10.1200/ testing guide

12. Manahan ER, Kuerer HM, Sebastian M, et al. Consensus Guidelines on Genetic Testing for Hereditary Breast Cancer from the American Society of Breast Surgeons. Ann Surg Oncol 2019;26(10):3025-3031 https://doi.org/10.1245/s10434-019-07549-8

13. Dreyer G. Familial and genetic cancers in gynaecology. S Afr J Gynaecol Oncol 2010;2(2):49-53. https://doi.org/10.1080/20742835.2010.11441160

14. Petrucelli N, Daly MB, Feldman GL. BRCA1- and BRCA2-associated hereditary breast and ovarian cancer. 1998 (updated 2016). In: Adam MP, Ardinger HH, Pagon RA, et al., eds. GeneReviews. Seattle, WA: University of Washington, 1993 - 2020. http://www.ncbi.nlm.nih.gov/books/NBK1247/ (accessed 20 May 2020).

15. Buys SS, Sandbach JF, Gammon A, et al. A study of over 35,000 women with breast cancer tested with a 25-gene panel of hereditary cancer genes. Cancer 2017;123(10):1721-1730. https://doi.org/10.1002/ a 25 -gene p
cncr.30498

16. Richards S, Aziz N, Bale S, et al. Standards and guidelines for the interpretation of sequence variants A joint consensus recommendation of the American College of Medical Genetics and Genomics and A joint consensus recommendation of the American College of Medical Genetics and Genomics and the Association fim. 2015.30
gis.

17. Tsaousis GN, Papadopoulou E, Apessos A, et al. Analysis of hereditary cancer syndromes by using a panel of genes: Novel and multiple pathogenic mutations. BMC Cancer 2019;19(1):535. https://do. org/10.1186/s12885-019-5756-4

18. Catana A, Apostu AP, Antemie R. Multi gene panel testing for hereditary breast cancer - is it ready to be used? Med Pharm Rep 2019;92(3):220-225. https://doi.org/10.15386/mpr-1083

19. Robson M, Dabney MK, Rosenthal G, et al. Prevalence of recurring BRCA mutations among Ashkenaz Jewish women with breast cancer. Genet Test 1997;1(1):47-51. https://doi.org/10.1089/gte.1997.1.47

20. Kromberg JGR, Sizer EB, Christianson AL. Genetic services and testing in South Africa. J Community Genet 2013;4(3):413-423. https://doi.org/10.1007/s12687-012-0101-5 